\title{
Temporal Hydrologic Alterations Coupled with Climate Variability and Drought for Transboundary River Basins
}

\author{
Ruqayah Mohammed ${ }^{1} \cdot$ Miklas Scholz $^{1,2}$. \\ Mohammad Zounemat-Kermani ${ }^{3}$
}

Received: 31 December 2015 /Accepted: 10 February 2017 /

Published online: 28 February 2017

(C) The Author(s) 2017. This article is published with open access at Springerlink.com

\begin{abstract}
Climate change (CC) and drought episode impacts linked with anthropogenic pressure have become an increasing concern for policy makers and water resources managers. The current research presents a comprehensive methodology but simple approach for predicting the annual streamflow alteration based on drought indices and hydrological alteration indicators. This has been achieved depending on the evaluation of drought severity and $\mathrm{CC}$ impacts during the human intervention periods to separate the influence of climatic abnormality and measure the hydrologic deviations as a result of streamflow regulation configurations. As a representative case study, the Lesser Zab River Basin in northern Iraq has been chosen. In order to analyse the natural flow regime, 34 hydrological years of streamflow (1931-1965) prior to the main dam construction were assessed. The Indicators of Hydrologic Alteration (IHA) method has been applied to quantify the hydrological alterations of various flow characteristics. In addition, an easy approach for hydrological drought prediction in relatively small basins grounded on meteorological parameters during the early months of the hydrological year has been presented. The prediction was accomplished by implementing the one-dimensional drought examination and the reconnaissance drought index (RDI) for evaluating the severity of meteorological drought. The proposed methodology is founded on linear regression relations connecting the RDI of 3, 6, and 12 months and the streamflow drought index (SDI). The results are critical for circumstances where an early exploration of meteorological drought is obtainable. Outcomes assist water resources
\end{abstract}

Electronic supplementary material The online version of this article (doi:10.1007/s11269-017-1590-0) contains supplementary material, which is available to authorized users.

Miklas Scholz

miklas.scholz@tvrl.lth.se

Division of Water Resources Engineering, Department of Building and Environmental Technology, Faculty of Engineering, Lund University, P.O. Box 118, 22100 Lund, Sweden

2 School of Computing, Science and Engineering, Civil Engineering Research Group, The University of Salford, Newton Building, Greater Manchester M5 4WT, UK

3 Department of Water Engineering, Shahid Bahonar University of Kerman, Kerman, Iran 
managers, engineers, policy makers and decision-makers responsible for mitigating the effects of CC.

Keywords Hydrological alteration indicator · Climate change · Decision-making ·

Reconnaissance drought index $\cdot$ Streamflow drought index $\cdot$ Water resources management

\section{Introduction}

\subsection{Background}

One of the main water-related hazards is drought (Mishra and Singh 2010), which is commonly considered as a three-dimensional episode categorised by its severity, duration and impacted region (Tsakiris and Vangelis 2005; Mohammed and Scholz 2017). There are numerous proposed methodologies for drought identifying, quantifying and monitoring. The most widespread methods, which are distinctive collections of indicators involving meteorological, hydrological and other data, are the drought indices (Tsakiris and Vangelis 2005; Mohammed and Scholz 2017).

Drought indices are vital and practical elements for characterising drought and supporting policy makers in mitigating its impacts on various water sectors. Noticeably, indices make it easier to transfer climate anomaly information to a wide range of audiences and assisting scientists in the evaluation of quantitative weather abnormalities in terms of their intensity, frequency, areal extent and duration (Mishra and Singh 2010; Yu et al. 2013).

A high number of meteorological drought indices with different intricacy have been utilised for various climatic conditions and objectives. Examples of the most common indices are as follows: Palmer drought severity index (PDSI), Palmer hydrological drought index (PHDI), standardised precipitation index (SPI), rainfall anomaly index (RAI), standardized anomaly index (SAI), deciles, percent of normal, crop moisture index (CMI), soil moisture drought index (SMDI), and surface water supply index (SWSI) as well as such indices based on the normalised difference vegetation index (NDVI). For more details of the most common indices, interested readers may refer to Heim (2002).

The SPI is considered by The World Meteorological Organisation as a universal drought index because of its capacity to be estimated for various reference periods adapting to the different response times of typical hydrological characteristics to precipitation (VicenteSerrano et al. 2015). The index permits exposure of various drought classifications affecting different regimes and regions. Still, there are shortages related to its failure to detect drought conditions estimated not by a shortage of precipitation $(\mathrm{P})$ but by a higher than normal aerial evaporative requirement, which is challenging (Tsakiris and Vangelis 2005; Cook et al. 2014). Therefore, recent drought trend studies (Shahidian et al. 2012; Vicente-Serrano et al. 2015) and drought scenarios under potential CC projections (Cook et al. 2014) depended on drought indices that take into account $\mathrm{P}$ and the aerial evaporative requirement.

Tigkas et al. (2015) introduced a brief overview of the theoretical basis of the reconnaissance drought index (RDI) together with some practical applications with a specialised software package called drought indices calculator (DrinC). The RDI is founded on two meteorological parameters, $\mathrm{P}$, which is observed, and the potential evapotranspiration (PET), which is estimated. 
Furthermore, cyclical river flow components anomaly such as high and low flows resulted from natural (i.e. climate change (CC)) and man-made (i.e. river damming) climatic conditions has produced enormous concerns expressed by hydrologists due to consequences for riverine ecosystems (Suen 2008; Doll and Zhang, 2010; Al-Faraj and Scholz 2014; Mittal et al. 2016). For estimation of the natural and altered hydrologic systems, a simple tool, which is known as the Indicator for Hydrologic Alteration (IHA), has been developed by The Nature Conservancy (The Nature Conservancy 2009). Through calculating the hydrologic characteristics for the preimpact and post- impact periods, the IHA can be utilised to assess how the stream system would be altered due to river regulation such as dam building.

Literature exposes that considerable research work has been undertaken to assess the hydrologic anomalies of natural flow regimes (Yan et al. 2010; Gao et al. 2013; Sun and Feng 2013; Jiang et al. 2014; Wang et al. 2016). Yet, most of the recent research has focused on the streamflow alteration from an ecological point of view (Suen 2008; Doll and Zhang 2010; Kim et al. 2011; Lee et al. 2014; Mittal et al. 2014; Stagl and Hattermann 2016) and not from a hydrological one. In addition, they did not consider to incorporate anthropogenic interventions, $\mathrm{CC}$ and drought event impacts within a comprehensive study.

Therefore, the prime aim of the study is to evaluate the streamflow hydrological anomalies due to anthropogenic interventions such as dam building, incorporated with $\mathrm{CC}$ and drought phenomena impacts, attempting to assess to what extent the anthropogenic intervention impacts linked with natural climatic phenomena would alter basin hydrological properties. Based on the authors' best knowledge, this is a novel effort at exploring the anthropogenic interventions, $\mathrm{CC}$ and drought severity effects on the basin hydrologic features.

\subsection{Aim and Objectives}

The major aim of this research is to investigate the impacts of $\mathrm{CC}$ and anthropogenic interventions on streamflow alteration in addition to the prediction of hydrological drought for relatively small basins based on meteorological data. The corresponding objectives are (a) to introduce a methodology for applying the climate forecasting system reanalysis (CFSR) dataset to attain historical meteorological data and to assess its applicability on CC studies, drought event estimations, and hydrological alteration detections; (b) to investigate the characteristics of spatio-temporal change of meteorological data at monthly and annual time scales; (c) to analyse the response of PET to the temperature variations; (d) to assess the temporal alteration of hydrologic regimes related to $\mathrm{CC}$ impacts coupled with anthropogenic interventions over the whole watershed; (e) to evaluate the potential $\mathrm{CC}$ impact, drought phenomenon and anthropogenic interventions on streamflow volume; and (f) to present a generic and simplified method for hydrological drought prediction in relatively small basins based on weather data.

\section{Theory}

\subsection{Trend Investigation}

In order to detect a trend in long time series of hydro-climatologic data, there are different tests that can be used such as parametric and non-parametric methods (Duhan and Pandey 2013). In 
this research, parametric (linear regression) and non-parametric (Mann-Kendall (M-K)) were used. The former method is distinguished by its simplicity and requires variables to be normally distributed (Tabari and Taalaee 2011). However, the latter technique has the advantage of not assuming any data distribution and is similarly powerful to its parametric competitors (Zhang et al. 2008). The following section briefly explains the applied methods.

\subsection{Parametric Method}

Simple linear regression is often performed to investigate the relationship between variables of interest and obtain the change of hydro-climatologic variables with time. A positive slope indicates a rising trend, whereas a negative slope is indicative of a decreasing trend. Another advantage for this test is that it gives a measure of significance founded on the hypothesis test regarding the slope and also delivers the magnitude of the degree of alteration (Hirsch et al. 1991). By multiplying the slope by the number of years, the total change during the period under observation can be received.

\subsection{Non-Parametric Method}

The $\mathrm{M}-\mathrm{K}$ test is a non-parametric method for assessing if there is a monotonic downward or upward trend of the parameter under consideration with time (Tabari and Taalaee 2011). A monotonic upward (downward) tendency indicates that the parameter consistently rises (declines) during the period. However, the trend might or might not be linear. The M-K test can be applied instead of a linear regression analysis, which can be applied to investigate if the slope of the predicted linear regression line is unlike zero. The regression analysis demands that the residuals from the fitted regression line are normally distributed. Such an assumption is not required by the $\mathrm{M}-\mathrm{K}$ test. For more details about $\mathrm{M}-\mathrm{K}$ test, readers may refer to previous studies (Tabari and Taalaee 2011; Robaa and AL-Barazanji 2013).

\subsection{Reconnaissance Drought Index (RDI)}

The reconnaissance drought index (RDI) can be shown in the alpha $\left(\mathrm{RDI}_{\alpha \mathrm{k}}\right)$, normalised $\left(\mathrm{RDI}_{\mathrm{n}}\right)$ and the standard $\left(\mathrm{RDI}_{\mathrm{st}}\right)$ forms. The $\mathrm{RDI}_{\mathrm{st}}$ can be used to assess the drought severity, whereas the $\mathrm{RDI}_{\alpha \mathrm{k}}$ can be used as an aridity index. The index is mainly founded on the aggregated $\mathrm{P}$ and PET theories. The $\mathrm{RDI}_{\alpha \mathrm{k}}$ is normally estimated for the $i$-th year at a time basis of $j$ successive months. The values of $\mathrm{RDI}_{\alpha \mathrm{k}}$ match both the lognormal and the gamma distributions in various positions.

A positive value of $\mathrm{RDI}_{\text {st }}$ relates to a wet period. In comparison, a negative value is indicative of a dry period in comparison to the natural conditions of the study region. The drought severity phenomena increase when $\mathrm{RDI}_{\text {st }}$ values are minimal. The drought severity can be classified into mild, moderate, severe and extreme classes. The corresponding limit values of $\mathrm{RDI}_{\mathrm{st}}$ are -0.5 to $-1.0,-1.0$ to $-1.5,-1.5$ to -2.0 , and $<-2.0$, respectively. The RDI is estimated for a hydrological year in 3-, 6-, 9- and 12 -month reference time periods. This indicates a variable quality of RDI compared to other drought indices since it is computed for pre-determined reference periods of time (Tigkas and Vangelis 2013). 


\subsection{Hydrological Drought Index}

The hydrological drought index (SDI) is founded on the cumulative streamflow volumes $\mathrm{S}_{\mathrm{i}, \mathrm{k}}$ for each reference period $\mathrm{k}$ of the $\mathrm{i}$-th hydrological year. For most small basins, streamflow may follow a skewed probability distribution. This can be approximated well by gamma distribution functions. The distribution is then transformed into normal. The SDI index can be defined by applying a two-parameter lognormal distribution.

A value of SDI greater than zero relates to a non-drought period. In comparison, a negative value is indicative of a drought period in comparison to the natural conditions of the study region. The hydrological drought severity increase when SDI values are minimal. The hydrological drought severity can be classified into mild, moderate, severe and extreme classes. The corresponding limit values of SDI are 0.0 to $-1.0,-1.0$ to $-1.5,-1.5$ to -2.0 , and $<-2.0$, respectively (Nalbantis 2008; Nalbantis and Tsakiris 2009). An integer number ranging from 0 (non-drought) to 4 (extreme drought) is usually considered.

\section{Materials and Methods}

\subsection{Representative Case Study Region}

The Lower Zab River (also known as Little Zab River and Lesser Zab River) is one of the main tributaries of the Tigris River, and is situated with its tributaries between latitudes $36^{\circ} 50^{\prime}$ $\mathrm{N}$ and $35^{\circ} 20^{\prime} \mathrm{N}$, and longitudes $43^{\circ} 25^{\prime} \mathrm{E}$ and $45^{\circ} 50^{\prime} \mathrm{E}$ (Mohammed and Scholz 2016); see also Online Resource 1.1. The Lower Zab River originates from the Zagros Mountains in Iran, and flows about $370 \mathrm{~km}$ south-east and south-west through north-western Iran and northern Iraq before joining the Tigris near Fatha city, which is located about $220 \mathrm{~km}$ north of Baghdad (Mohammed et al. 2017), with a total length of approximately $302 \mathrm{~km}$ and about $80 \mathrm{~km}$ south of the Greater Zab River.

There are a number of tributaries contributing to the river discharge such as the Banah and Qazlaga. The catchment area of the Lower Zab Basin (LZRB) and its tributaries is approximately $19,254 \mathrm{~km}^{2}$ with nearly $76 \%$ of the basin located in Iraq. The mean annual storage of the Lower Zab at Dokan and at the downstream station of Altun Kupri-Goma is about 6 billion cubic meters $(\mathrm{BCM})$ and $7.8 \mathrm{BCM}$ in this order. The corresponding mean contribution to the Tigris of $191 \mathrm{~m}^{3} / \mathrm{s}$ and $249 \mathrm{~m}^{3} / \mathrm{s}$ for the two stations, respectively (Mohammed et al. 2017).

Online Resource 1.2 indicates the average annual flow variability of the river Zab, which is characterised by regular oscillation of dry and wet periods at both gauging stations (USGS 2010). The mean, maximum and minimum discharges of the Lower Zab are 227, 3420 and $6 \mathrm{~m}^{3} / \mathrm{s}$, respectively (Al-Ansari et al. 2014; Mohammed et al. 2017). The Lower Zab crosses rather diverse ecological and climatic zones. Annual $\mathrm{P}$ along the river course decreases from more than 1000 in the Iranian Zagros to less than $200 \mathrm{~mm}$ at the confluence with the river Tigris. Moreover, mean temperatures follow the same gradient. The mountain valleys are usually subjected to colder winters than the corresponding foothill areas. However, summers in the latter are usually hotter (NOAA 2009).

Dokan is the main dam that has been constructed in the Iraqi portion of the LZRB, whereas Iran is recently constructing one dam with two others in the planning phase. The Dokan, which is a multi-purpose arch dam, was constructed between 1957 and 1961 upstream from Dokan town with a maximum capacity of approximately 6970 million cubic meters (MCM), crest 
height of $116 \mathrm{~m}$ above the river bed $(516 \mathrm{~m})$ and a length of $360 \mathrm{~m}$. The main dam functions are to control the discharge of the Lower Zab, store water for irrigation and to provide hydroelectric power.

\subsection{Climate Forecasting System Reanalysis Data}

Gathering representative weather data for basin-scale hydrological simulations might be challenging and take a lot of time. This is because the land-based meteorological stations do not usually adequately cover the climate observed over a basin for many reasons such as that they might be located far from the area of interest and are associated with missing data, which holds true for the case study area.

Accordingly, this research introduces a procedure for utilising the CFSR global methodological dataset (Saha et al. 2010) to gain historical meteorological data and investigate its applicability for hydrologic alteration, drought severity assessment and CC studies. The CFSR data are based on a dataset created by the National Centres for Environmental Prediction (NCEP) as a part of a climate forecast system (Chen and Emily 2014; Dile and Srinivasan 2014; Saha et al. 2014).

The CFSR dataset supersedes the previous National Centers for Environmental Prediction (NCEP)/National Center for Atmospheric Research (NCAR) reanalysis dataset that has been immensely utilised in previous down-scaling research (e.g., Michelangeli et al. (2009) and Maurer et al. (2010)). Recent research in water resources (Srinivasan 2014; Adeloye et al. 2016; Soundharajan et al. 2016; Mohammed and Scholz 2017) dependent on the CFSR dataset. For example, Mohammed and Scholz (2017) confirmed the CFSR data reliability by applying the dataset to evaluate the potential effect of evapotranspiration formulations at different elevations and climatic conditions on the RDI index. The CFSR dataset covers the period from 1979 to 2014 with a spatial resolution of $0.5^{\circ} \times 0.5^{\circ}$ (Soundharajan et al. 2016). Concerning data reliability in watershed-scale modelling, Fuka et al. (2013) confirmed that applying the CFSR data as input to the hydrological model produces streamflow, which are as accurate as or even better than models derived through popular meteorological stations, particularly in the case that the stations are located greater than $10 \mathrm{~km}$ from the area of interest.

\subsection{Information Availability and Application of the Method to the Case Study}

Daily meteorological data from 30 stations were available for the period between 1979/80 and 2013/14. Daily streamflow data were accessible for Dokan station for the duration of 82 years.

ArcGIS 10.3 has been used for meteorological station location projections, Thiessen network computations, spatial analysis of the meteorological data and river basin delineation using the world borders, Iraqi Shapefiles and Lower Zab River basin files, which have been downloaded from Thematic Mapping (2009), the database of Global Administrative Areas (GADM 2012), the Global and Land Cover Facility (GLCF 2015), which is a centre for land cover science with a concentrate on study using remotely sensed satellite data and products to access land cover change for regional to universal systems, respectively.

Statistical analyses for the daily data, including monthly and annual average values, corrections and gap filling were performed using the Statistical Program for Social Sciences (SPSS) 20. Online Resource 1.3 shows the categories of the meteorological stations for the studied basin. Online Resources 1.4 and 1.5 reveal both the parametric and non-parametric 
tests for the meteorological variables. The estimation of PET and RDI was accomplished with a specialised software package named DrinC (Tigkas et al. 2015).

In order to achieve an accurate estimation of the spatial distribution of rainfall, it is necessary to use interpolation methods. The weighing mean method was considered as the most important one for engineering praxis (Fiedler 2003). This method assigns weights at each gauging station in proportion to the basin area, which is closest to that station.

To set up the method, the following steps have been accomplished using ArcGIS 10.3. The creation of a shapefile of the named watershed polygons as a function of the land cover image has been achieved by downloading the relevant information from GLCF (2015)

This step was followed by creation of two shapefiles. The first one is the basin border polygon, while the second one is the point shapefile that represents meteorological stations. Each representative point involved a value of the long-term P.

A Thiessen network (Online Resource 1.6) was created to estimate the area of each station polygon $\left(\mathrm{a}_{\mathrm{i}}\right)$. This has been achieved depending on the following: (a) Connecting the adjacent stations with lines; (b) Constructing perpendicular bisectors of each line, and (c) The bisectors are extended and applied to form the polygon around each station. Online Resource 1.7 lists the station addresses with corresponding average $\mathrm{P}$ and the sub-area sizes.

Rainfall values for each gauging station $\left(\mathrm{P}_{\mathrm{i}}\right)$ are multiplied by the area of each polygon $\left(\mathrm{a}_{\mathrm{i}}\right)$. The next step required the computation of the average values of the $\mathrm{P}_{\mathrm{av}}$ by summing up all values obtained from the previous step and dividing the number by the total basin area according to equation (1).

$$
\mathrm{P}_{\mathrm{av}}=\frac{\sum_{\mathrm{i}=1}^{\mathrm{n}} \mathrm{a}_{\mathrm{i}} \times \mathrm{P}_{\mathrm{i}}}{\sum_{\mathrm{i}=1}^{\mathrm{n}} \mathrm{a}_{\mathrm{i}}}
$$

where $\mathrm{P}_{\mathrm{av}}$ is the average value of the basin $\mathrm{P}(\mathrm{mm}), \mathrm{P}_{\mathrm{i}}$ is the average value of the station polygon $\mathrm{P}(\mathrm{mm})$ and $\mathrm{a}_{\mathrm{i}}$ is the meteorological station area. Stations are distributed both inside and outside the polygons (Online Resource 1.6). Only one P value per station has been provided to keep the procedure simple. To evaluate the deviation of the natural flow regime that resulted from $\mathrm{CC}$ and drought phenomena linked to the anthropogenic interventions, the Indicators of Hydrologic Alteration software version7.1 (Richter et al. 1998; The Nature Conservancy 2009) has been utilised.

The daily Lower Zab River flow rate ranged from 1931 to 2013 and was measured at the Iraqi side of the river. The entire records were separated into two prime categories: natural flow period and changed flow period. The first hydrological alteration has occurred in the water year 1965, which was considered as a reference water year. Accordingly, the period between 1931 and 1964 represent the pre-regulated period. However, the period that covers the hydrologic years between 1965 and 2013, which was considered as the post-regulated period.

The time intervals selected depended on the degree of anthropogenic interventions such as increasing water requirements and reservoir constructions in addition to the impact of CC. The first period between 1965 and 2013 represents the entire period since the first reservoir was constructed. The period between 1979 and 2014 was characterised by variation in climate involving two sub-periods (1979-1987 and 1998-2008). The developed methodology enhanced understanding of the separate elements of the hydrologic variations in the streamflow. Furthermore, Online Resource 1.8 shows the normal P years during the studied period. 


\section{Results and Discussion}

\subsection{Historical Trends of the Meteorological Parameters}

This research is based on the CFSR global methodological dataset, which is used to investigate its applicability for streamflow alteration estimations, drought severity computations and CC studies. The considered datasets represent various elevations, which ranged from $178 \mathrm{~m}$ to $2420 \mathrm{~m}$ over the case study basin. Online Resource 1.6 visualises the spatial distribution of the stations. Online Resource 1.3 shows the categories and locations of the chosen meteorological stations.

Before using the dataset, it is critical to assess its validity by assessing the correlation coefficients between variables collected from land-based stations and the CFSR. Online Resource 1.9 indicates that there is a strong correlation between the two datasets.

In order to detect the decadal trend of the key meteorological parameters, both parametric and non-parametric tests have been accomplished. Online Resource 1.4 reveals the analysis for $\mathrm{P}$ and air temperature for 30 meteorological stations over the studied area for the period between 1979 and 2014. Based on the outcome of the statistical analysis. Online Resource 1.10 shows the trend for the mean air temperature, $\mathrm{P}$ and PET over the basin. The analysis reveals that there is a significantly positive trend in annual $\mathrm{T}_{\max }$ at about $90 \%(\mathrm{p}<0.01)$ and $10 \%(\mathrm{p}<0.05)$ of the stations, respectively. Moreover, significant warming trends in annual $\mathrm{T}_{\max }$ varied from $1.909{ }^{\circ} \mathrm{C}$ to $0.370{ }^{\circ} \mathrm{C}$ per decade. The trend rates of $\mathrm{T}_{\max }$ have been usually stronger than those in the $\mathrm{T}_{\min }$ series. Some previous studies have reported similar conclusions in the selected region (Robaa and AL-Barazanji 2013; UNESCO 2014).

Regarding the historical changes for the third meteorological variable PET, the statistical analysis showed that the long-term PET has increased significantly by nearly $77(p<0.01)$ and $23 \%(p<0.05)$ of the considered stations, respectively, with a decadal growth that reached its maximum value that is approximately $36 \mathrm{~mm}$ (Online Resource 1.5). Both changes have contributed significantly to the reduction of the streamflow and indicated that the lower Zab river basin has witnessed CC. Variation in climate produced an alteration in precipitation, air temperature and PET, which widened the gap between the basin water storage availability and the corresponding water demand.

\subsection{Drought Identification and Classification}

For the purpose of drought occurrence detection, the RDI (Tsakiris and Vangelis 2005) was calculated using the available data for $\mathrm{P}$ and the estimated values of PET. The index is classified as a meteorological drought index because it depends essentially on meteorological parameters observed for various meteorological stations. To evaluate different types of droughts, a three-month RDI (3 RDI) is computed for a short-term meteorological drought evaluation, a six-month RDI (6 RDI) is estimated for agricultural drought, and a 12-month RDI (12 RDI) is used as an intermediate long-term drought index for hydrological drought analyses and applications (USGS 2010).

Online Resource 1.11 presents the $\mathrm{RDI}_{\mathrm{st}}$ values estimated for the studied area based on data from 1979 to 2014 as well as long-term $\mathrm{P}_{\mathrm{av}}$ and indicates that a non-uniform cyclic pattern of drought and wet periods was observed for the studied area concerning the studied time span. Evident seasonal droughts were recorded for five years during the examined record; particularly for 1998/1999, 1999/2000, 2000/2001, 2007/2008 and 2008/2009 (average RDI values - 


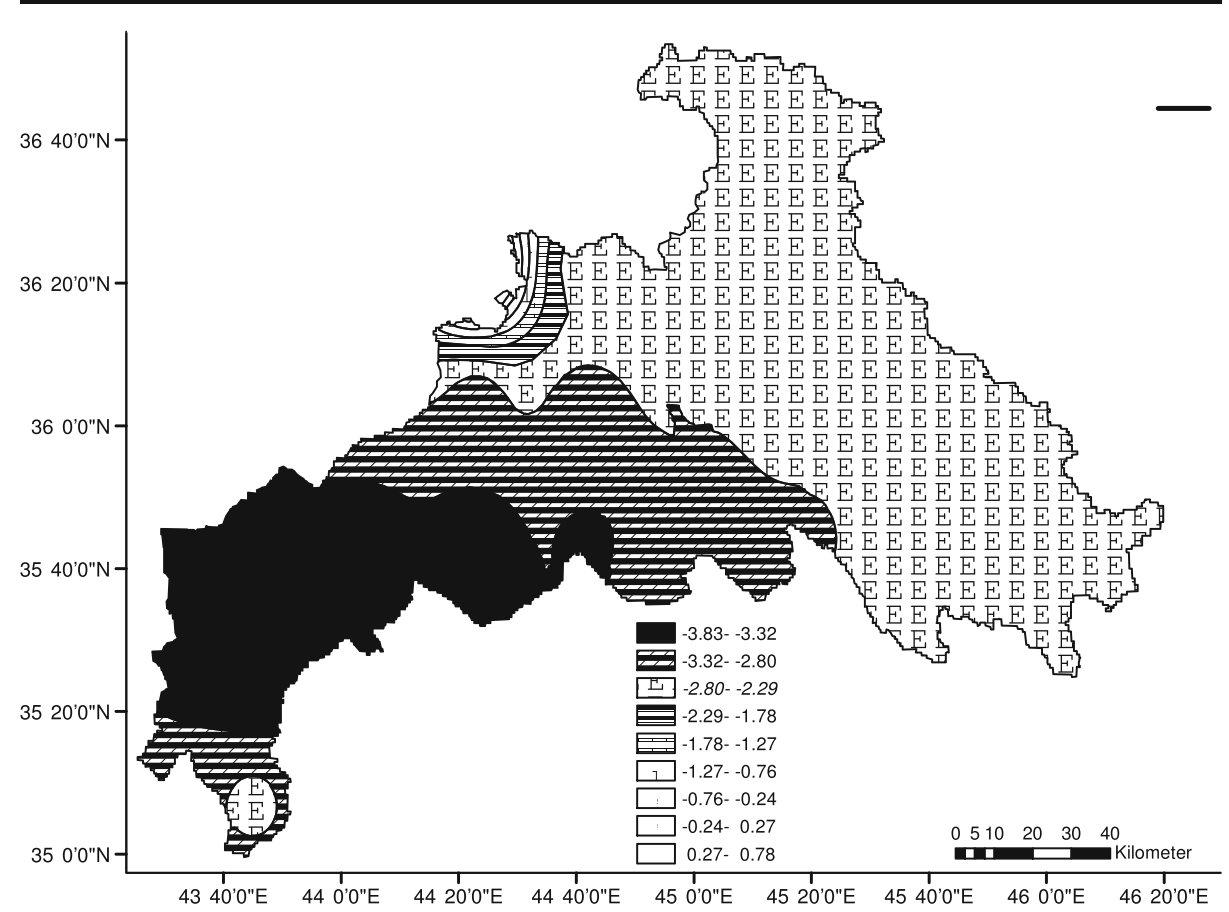

Fig. 1 The spatial distribution of the worst drought that occurred in the case study region during the water years 2007 and 2008

$1.84,-1.67,-1.45,-2.91$ and -1.53 , respectively), which were also reported by many earlier studies such as Fadhil (2011) and UNESCO (2014). Figure 1 shows the spatial distribution of the worst drought that occurred in the region during the water year 2007/2008. Generally speaking, droughts usually happen at the beginning of the wet season, which is reflected by either a decline in the $\mathrm{P}$ amount or a delay in $\mathrm{P}$ events.

As the RDI analysis shows, the drought severity over the studied basin has worsened significantly during the past twelve years. The RDI values computed between 1998 and 2011 show that critical droughts happened as the number of months with extended periods of $\mathrm{P}$ shortage increased. As shown in the $\mathrm{P}$ trend and the long-term analysis, the drought phenomenon was accompanied by a decrease in P. In addition, the P trend from the beginning of 2000 indicates that the region has been experiencing a reduction in rainfall and water resources in addition to an increase in drought periods.

\subsection{Assessment of Anthropogenic Interventions Linked to Climate Variability}

The potential effects of $\mathrm{CC}$ detection on the hydro-climatologic variables can be considered as a substantial step in the $\mathrm{CC}$ impacts analysis linked with anthropogenic interventions. The main consequence of $\mathrm{CC}$ is that the wet and dry years are characterised by high and low flows in that order. Yoo (2006) proposed that the proper periods in which annual basin $\mathrm{P}$ is more than Average $\mathrm{P}\left(\mathrm{P}_{\mathrm{av}}\right)+0.75 \times$ Standard Deviation $(\mathrm{SD})$ are considered as wet years, whereas, years with annual $\mathrm{P}$ no more than $\mathrm{P}_{\mathrm{av}}-0.75 \times \mathrm{SD}$ are considered as dry years. Therefore, hydrological years with annual $\mathrm{P}$ values between these two thresholds are considered as normal years $\mathrm{P}_{\mathrm{av}^{-}}$ 


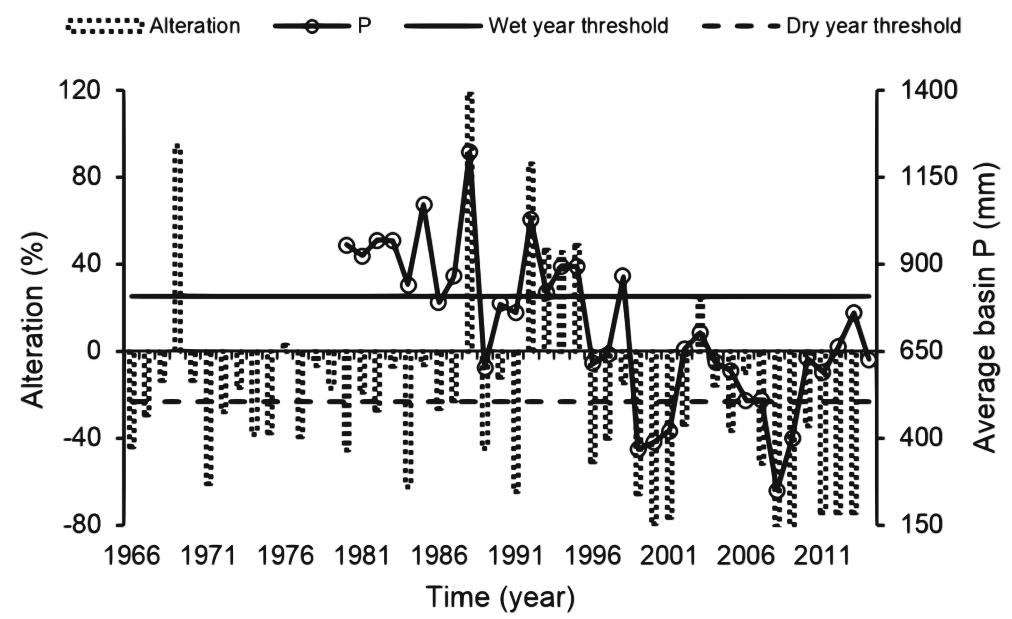

Fig. 2 Annual median anomaly for the time period between 1966 and 2014 with both wet and dry year thresholds coupled with long-term average precipitation over the study area for the time span between 1979 and 2014

$0.75 \times \mathrm{SD} \leq \mathrm{P} \leq \mathrm{P}_{\mathrm{av}}+0.75 \times \mathrm{SD}$ (Yang et al. 2008). Figure 2 shows streamflow time series corresponding to normal hydrological years with wet and dry year thresholds.

On one hand, the annual alteration ratio of the entire changed timespan (1964-2013) compared to the long-term median yearly discharge for the unchanged period (1932-1964) was calculated according to equation (2).

$$
\text { LZR flow alteration } \%=\frac{\text { LZR altered flow }- \text { LZR unaltered flow }}{\text { LZR unaltered flow }} \times 100
$$

where $\mathrm{LZR}_{\text {altered }}$ and $\mathrm{LZR}_{\text {unaltered }}\left(\mathrm{m}^{3} / \mathrm{s}\right)$ are the median yearly changed discharge and longterm median annual natural flow for the entirely unaltered condition in this order. Figure 2 shows the anomalies of the median annual flow for the post-regulation condition based on the long-term pre-regulation median annual flow.

On the other hand, Fig. 2 reveals that the water year 1987 experienced a significant increase in the basin $\mathrm{P}_{\mathrm{av}}$ of nearly $44 \%$ more than the normal year maximum threshold. The considerable increase in $\mathrm{P}$ results in a substantial alteration in the streamflow to about $118 \%$, with the corresponding annual mean flow volume of $2.31 \times 10^{9} \mathrm{~m}^{3}$ (Online Resource 1.12). However, the entire opposite was recorded for the hydrological periods 1998-2001 and 2006-2008 (Online Resource 1.13). These two periods experienced a steep decline in the basin $\mathrm{P}_{\mathrm{av}}$ to nearly 40 and $60 \%$ in that order. The reduction in $\mathrm{P}_{\mathrm{av}}$ led to a substantial decline in the Lower Zab streamflow by around 66,77 and $79 \%$ with the corresponding yearly mean flow volumes of $0.35 \times 10^{9}, 0.31 \times 10^{9}$, and $0.34 \times 10^{9} \mathrm{~m}^{3}$ for the period between 1998 and 2001 . However, the hydrological period between 2006 and 2008 experienced approximately 52, 80 and 83\% streamflow reductions with $0.76 \times 10^{9}, 0.29 \times 10^{9}$ and $0.31 \times 10^{9} \mathrm{~m}^{3}$ annual mean flow volumes. Furthermore, between 1991 and 2013, the normal flow regime has been experienced a sharp reduction during which the flow alteration fluctuated between -75 and $86 \%$ with $0.31 \times 10^{9}$ and $1.24 \times 10^{9} \mathrm{~m}^{3}$ maximum and minimum yearly average storage volumes in that order. Findings of this research proved that $\mathrm{CC}$ has negatively affected the Lower Zab river storage water availability. 


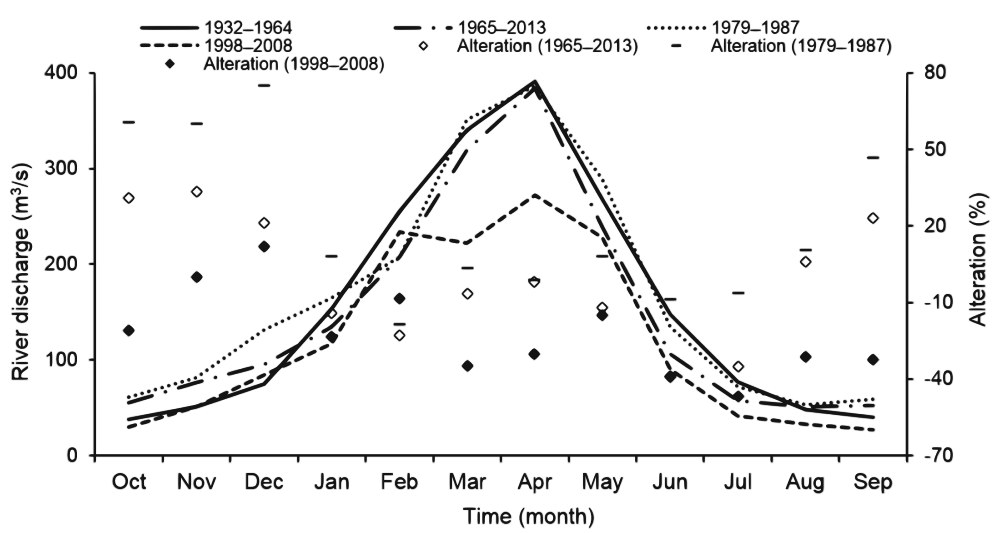

Fig. 3 The long-term median monthly flows of the pre-altered and the three altered time scales coupled with their anomies

Moreover, the alteration in monthly median flows corresponding to the long-term natural flow regime and the three changed time scales and their related alteration is visualised in Fig. 3. The alteration during the two altered time spans of the periods 1965-2013 and 19791987 could be considered relatively close to each other, particularly through the rainy months. The small variations can be assigned to the CC impacts, which was noticeable from the water year 1998 onward. The dramatic alteration during the non-rainy months assigned to the effect of human-induced and CC pressure in the upper part of the studied area, which in turn decreases watershed storage system availability.

\subsection{Predicting Equation}

For the reference periods of 3, 6, and 12 months, $\mathrm{RDI}_{\text {st }}$ estimations were achieved. The linear regression lines between $\operatorname{RDI}_{\mathrm{st}}(3,6$, and 12 months) and SDI (12 months) for the water years $1979 / 80$ to $2013 / 14$ are presented in Fig. 4. The evapotranspiration values needed for the RDI calculations were estimated applying the FAO PenmanMonteith methodology (Allen et al. 1998). This equation has been increasingly gaining acceptance and is used throughout the world for reference evapotranspiration estimations (Shahidian et al. 2012). The method requires the measurement of several climatic variables such as temperature, relative humidity, solar radiation and wind speed, which are available for this research.

As the reference periods become longer, the regression equations reveal better fits, as represented by higher correlation coefficients (Fig. 4). This can be expected, because an improve correlation is obtained by including extra data associated to the hydrological drought of the assessed year. This has been achieved for a reference period of up to 9 months by which $\mathrm{P}$ and streamflow co-exist. Regression equations can introduce predicts with rather high variability. Accordingly, each SDI prediction should be treated only as a representative value, particularly if it is calculated applying data from the first trimester of the water year. It follows that, this relatively simple method, which introduces findings with substantial variability, demonstrates to be valuable since pro-active measures to mitigate the effects of droughts are decided upon the class of severity category of the expected drought event and not on the absolute SDI value. 
(a)

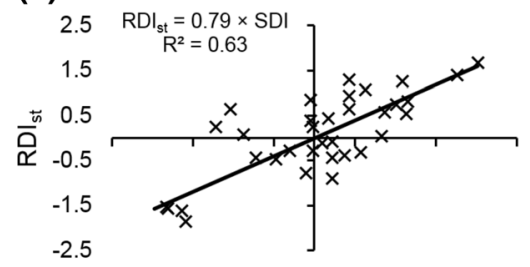

(c)

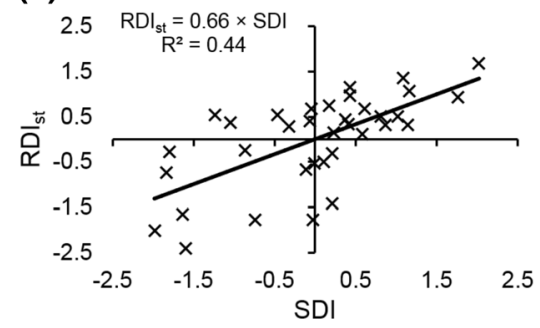

(b)

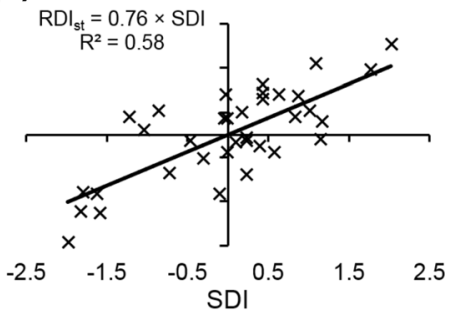

Fig. 4 Annual streamflow drought index (SDI) forecasting equations based on the standardised reconnaissance drought index $\left(\mathrm{RDI}_{\mathrm{st}}\right)$ for the reference time periods of 12,6 and 6 months: (a) $\mathrm{RDI}_{\mathrm{st}}$ (12 months) - SDI (12 months), (b) RDI (6 months) - SDI (12 months) and (c) RDI (3 months) - SDI (12 months), respectively

\section{Conclusions}

The current research presents a generic method to support water resources managers to create informed and robust judgements on adaptation and mitigation policies in the face of CC. The following case study-specific conclusions could be drawn:

- The regular periodic drought and rainy periods were recorded for the considered period.

- Noticeable droughts on a seasonal basis were observed for five years during the considered historical records, particularly in 1998/1999, 1999/2000 and 2000/2001.

- The $\mathrm{P}$ trend along with the $\mathrm{RDI}_{\mathrm{st}}$ calculation, beginning from 2000, reveals that the region has been witnessing a P decline and water resources as well as drought period increases.

- During the water year 2007/2008, the drought severity has worsened dramatically.

- The hydrological year 1987/1988 experienced a substantial rise in the basin $\mathrm{P}_{\mathrm{av}}$ due to considerable streamflow alteration.

- The hydrological periods 1998-2002 and 2006-2008 experienced a steep $\mathrm{P}_{\mathrm{av}}$ reduction over the studied basin, which caused a streamflow reduction by more than $80 \%$.

- The dramatic alteration during the non-rainy months attributed to the effect of humaninduced and CC pressure in the upper part of the studied area, which in turn reduced the watershed storage capacity.

Acknowledgements The research presented has been financially supported by the Iraqi Government via Babylon University (PhD studentship for the lead author).

\section{Compliance with Ethical Standards}

Conflict of Interest The authors declare that they have no conflict of interest. 
Open Access This article is distributed under the terms of the Creative Commons Attribution 4.0 International License (http://creativecommons.org/licenses/by/4.0/), which permits unrestricted use, distribution, and reproduction in any medium, provided you give appropriate credit to the original author(s) and the source, provide a link to the Creative Commons license, and indicate if changes were made.

\section{References}

Adeloye AJ, Soundharajan BS, Ojha CSP, Remesan R (2016) Effect of hedging-integrated rule curves on the performance of the pong reservoir (India) during scenario-neutral climate change perturbations. Water Resour Manag 30(2):445-470. doi:10.1007/s11269-015-1171-z

Al-Ansari NA, Ali AA, Knutsson S (2014) Present conditions and future challenges of water resources problems in Iraq. J Wat Res Prot 6(12):1066-1098. doi:10.4236/jwarp.2014.612102

Al-Faraj F, Scholz M (2014) Assessment of temporal hydrologic anomalies coupled with drought impact for a transboundary river flow regime: the Diyala watershed case study. J Hydrol 517:64-73

Allen RG, Pereira LS, Raes D, Smith M (1998) Crop evapotranspiration: Guidelines for computing crop water requirements. Food and Agriculture Organization (FAO) Irrigation and Drainage Paper 56, first ed, Rome

Chen M, Emily B (2014) The NCEP climate forecast system version 2. J Clim 27(6):2185-2208

Cook BI, Smerdon JE, Seager R, Coats S (2014) Global warming and 21st century drying. Clim Dyn 43(9): 2607-2627

Dile YT, Srinivasan R (2014) Evaluation of CFSR climate data for hydrologic prediction in data-scarce watersheds: an application in the Blue Nile River Basin. J Am Water Resour Assoc 50(5):1226-1241

Doll P, Zhang J (2010) Impact of climate change on freshwater ecosystems: a global-scale analysis of ecologically relevant river flow alterations. Hydrol Earth Syst Sci 14(5):783-799

Duhan D, Pandey A, Gahalaut KPS, Pandey RP (2013) Spatial and temporal variability in maximum, minimum and mean air temperatures at Madhya Pradesh in central India. Compt Rendus Geosci 345:3-21

Fadhil MA (2011) Drought mapping using Geoinformation technology for some sites in the Iraqi Kurdistan region. Int J Digit Earth 4(3):239-257

Fiedler FR (2003) Simple, practical method for determining station weights using Thiessen polygons and isohyetal maps. J Hydrol Eng 8(4):219-221

Fuka DR, Walter MT, MacAlister C, Degaetano AT, Steenhuis TS, Easton ZM (2013) Using the climate forecasting system reanalysis as weather input data for watershed models. Hydro Proc 28(22):5613-5623

GADM (2012) Global Administrative Areas database. http://www.gadm.org. Accessed 10 March 2015

GLCF (2015) Global and Land Cover Facility. http://www.landcover.org/data/srtm/ Accessed 50 March 2015

Gao D, Yang H (2013) Impact of the Three Gorges Dam on flow regime in the middle and lower Yangtze River Bing. Quat Int 304(2013):43-50

Heim RR Jr (2002) A review of twenty-century drought indices used in the United States. Bull Am Meteorol Soc 83(8):1149-1165

Hirsch RM, Alexander RB, Smith RA (1991) Selection of methods for the detection and estimation of trends in water quality. Water Res Res 27(5):803-814

Jiang BX, Wang X, Cai X (2014) Assessment of hydrologic alterations caused by the Three Gorges Dam in the middle and lower reaches of Yangtze River, China. Water 6(5):1419-1434

Kim BS, Kim BK, Kwon HH (2011) Assessment of the impact of climate change on the flow regime of the Han River basin using indicators of hydrologic alteration. Hydrol Process 25(5):691-704. doi:10.1002/hyp.7856

Lee A, Cho S, Kang DK, Kim S (2014) Analysis of the effect of climate change on the Nakdong river stream flow using indicators of hydrological alteration. J Hydro-Environ Res 8(3):234-247. doi:10.1016/j.jher.2013.09.003

Maurer EP, Hidalgo HG, Das T, Dettinger MD, Cayan DR (2010) The utility of daily large-scale climate data in the assessment of climate change impacts on daily streamflow in California. Hydrol Earth Syst Sci 14(6):1125-1138

Michelangeli PA, Vrac M, Loukos H (2009) Probabilistic downscaling approaches: application to wind cumulative distribution functions. Geophys Res Lett 36(11):1-6

Mishra KA, Singh VP (2010) A review of drought concepts. J Hydrol 391(1-2):202-216

Mittal N, Mishra A, Singh R, Bhave AG, van der Valk M (2014) Flow regime alteration due to anthropogenic and climatic changes in the Kangsabati River, India. Ecohydrol Hydrobiol 14(3):182-191

Mittal N, Bhave AG, Mishra A, Singh R (2016) Impact of human intervention and climate change on natural flow regime. Water Resour Manag 30(2):685-699. doi:10.1007/s11269-015-1185-6

Mohammed R, Scholz M (2016) Impact of climate variability and streamflow alteration on groundwater contribution to the base flow of the Lower Zab River (Iran and Iraq). Environ Earth Sci 75:1392. doi:10.1007/s12665-016-6205-1 
Mohammed R, Scholz M (2017) Impact of evapotranspiration formulations at various elevations on the reconnaissance drought index. Water Res Manag 31(1):531-548. doi:10.1007/s11269-016-1546-9

Mohammed R, Scholz M, Nanekely MA, Mokhtari Y (2017) Assessment of models predicting anthropogenic interventions and climate variability on surface runoff of the Lower Zab River. Stoch Environ Res Risk Assess. doi:10.1007/s00477-016-1375-7

Nalbantis I (2008) Drought and streamflow. Eur Water 23(24):65-76

Nalbantis I, Tsakiris G (2009) Assessment of hydrological drought revisited. Water Res Manag 23(5):881-897

NOAA (2009) National Oceanic and Atmospheric Administration Climate of Iraq. https://www.ncde.noaa. gov/oa/climate/afghan/iraq-narrative.html. Accessed 4 November 2015

Richter B, Baumgartner JV, Braun DP, Ponell J (1998) A spatial assessment of hydrologic alteration within a river network. Regul Riv: Res Manag 14(4):329-340

Robaa SM, AL-Barazanji ZJ (2013) Trends of annual mean surface air temperature over. Iraq Nat Sci 11(12):138-145

Saha S, Moorthi S, Pan HL, Behringer D, Stokes D, Grumbine R, Hou YT, Chuang HY, Juang HMH, Sela J, Iredell M, Treadon R, Keyser D, Derber J, Ek M, Lord S, Dool HVD, Kumar A, Wang W, Long C, Chelliah M, Xue Y, Schemm JK, Ebisuzaki W, Xie P, Higgins W, Chen Y, Wu X, Wang J, Nadiga S, Kistler R, Woollen J, Liu H, Gayno G, Wang J, Kleist D, Van Delst P, Meng J, Wei H, Yang R, Chen M, Zou CZ, Han Y, Cucurull L, Goldberg M, Liu Q, Rutledge G, Tripp P, Reynolds RW, Huang B, Lin R, Zhou S (2010) The NCEP climate forecast system reanalysis. Bull Am Meteorol Soc 91(8):1015-1057

Saha S, Moorthi S, Wu X, Wang J, Nadiga S, Tripp P, Behringer D, Hou YT, Chuang H, Iredell M, Ek M, Meng J, Yang R, Mendez MP, Doll HVD, Zhang Q, Wang W (2014) The NCEP climate forecast system version 2. J Clim 27(6):2185-2208

Shahidian S, Serralheiro R, Serrano J, Teixeira J, Haie N, Santos F (2012) Hargreaves and other reduced-set methods for calculating evapotranspiration. In: Evapotranspiration - 15 Remote Sensing and Modeling (ed) Irmak, A., InTech, Rijeka, pp 60-80

Soundharajan BS, Adeloye AJ, Remesan R (2016) Evaluating the variability in surface water reservoir planning characteristics during climate change impacts assessment. J Hydrol 538:625-639. doi:10.1016/j. jhydrol.2016.04.051

Stagl JC, Hattermann FF (2016) Impacts of climate change on riverine ecosystems: alterations of ecologically relevant flow dynamics in the Danube River and its major tributaries. Water 8(12):566. doi:10.3390/w8120566

Suen JP (2008) Potential impacts to freshwater ecosystems caused by flow regime alteration under changing climate conditions in Taiwan. Hydrol Earth Syst Sci Discuss 5(6):3005-3032

Sun T, Feng ML (2013) Multistage analysis of hydrologic alterations in the Yellow River, China. River Res Appl 29(8):991-1003. doi:10.1002/rra.2586

Tabari H, Taalaee PH (2011) Analysis of trend in temperature data in arid and semi-arid regions of Iran. Glob Planet Change 72:1-10

Thematic Mapping (2009). http://thematicmapping.org/downloads/world_borders.php. Accessed 2 October 2015

The Nature Conservancy (2009) Indicators of hydrologic alteration version 7.1 user's manual. The Nature Conservancy, June, 76

Tigkas D, Vangelis H, Tsakiris G (2015) DrinC: a software for drought analysis based on drought indices. Earth Sci Inform 8(3):697-709

Tsakiris G, Vangelis H (2005) Establishing a drought index incorporation evapotranspiration. Eur Wat 9(10):3-11

UNESCO (2014) United Nations Educational, Scientific and Cultural Organization. Integrated Drought Risk Management-DRM National Framework for Iraq. An analysis report. Retrieved from http://unesdoc.unesco. org/images/0022/002283/228343E.pdf UN-ESCWA and BGR (United Nations Economic and Social Commission for Western Asia; Bundesanstalt für Geowissenschaften und Rohstoffe) (2013) Inventory of Shared Water Resources in Western Asia, Beirut

USGS (2010) U.S. Geological Survey. Stream Gage Descriptions and Streamflow Statistics for Sites in the Tigris River and Euphrates River Basins, Iraq. Data Series 540

Vicente-Serrano SM, Schrier GVD, Begueria S, Azorin-Molina C, Lopez-Moreno J (2015) Contribution of precipitation and reference evapotranspiration to drought indices under different climates. J Hydrol 526:42-54

Wang Y, Rhoads BL, Wang D (2016) Assessment of the flow regime alterations in the middle reach of the Yangtze River associated with dam construction: potential ecological implications. Hydrol Process 30(21):3949-3966. doi:10.1002/hyp.10921

Yan Y, Yang Z, Liu Q, Sun T (2010) Assessing effects of dam operation on flow regimes in the lower Yellow River. Proc Environ Sci 2:507-516. doi:10.1016/j.proenv.2010.10.055

Yang T, Zhang Q, Xu C-Y, Chen X (2008) A spatial assessment of hydrologic alteration caused by dam construction in the middle and lower Yellow River, China. Hydrol Process 22(18):3829-3843

Yoo C (2006) Long term analysis of wet and dry years in Seoul, Korea. J Hydrol 318(1-4):24-36

Yu W, Shao M, Ren M, Zhou H, Jiang H, Li D (2013) Analysis on spatial and temporal characteristics drought of Yunnan Province. Acta Ecol Sin 33(3):317-324 